\title{
Collective Obligations: Their Existence, Their Explanatory Power, and Their Supervenience on the Obligations of Individuals
}

\author{
Bill Wringe
}

\begin{abstract}
In this paper I discuss a number of different relationships between two kinds of (moral) obligation: those which have individuals as their subject, and those which have groups of individuals as their subject. I use the name collective obligations to refer to obligations of the second sort. I argue that there are collective obligations, in this sense; that such obligations can give rise to and explain obligations which fall on individuals; that because of these facts collective obligations are not simply reducible to individual obligations; and that collective obligations supervene on individual obligations, without being reducible to them. The sort of supervenience I have in mind here is what is sometimes called 'global supervenience'. In other words, there cannot be two worlds which differ in respect of the collective obligations which exist in them without also differing in respect of the individual obligations which exist in them.
\end{abstract}

\section{Introduction}

One might expect the notion of collective obligation-if there is a single such notion, and if it is a coherent one-to play a central role in political philosophy; or at least in that sort of political philosophy which is concerned with the working out of the implications of general principles about how human beings ought to treat one another within the political domain-what one might call, not necessarily pejoratively, moralised political philosophy. ${ }^{1}$ For one plausible, though perhaps controversial way of demarcating that domain is that it is the one in which groups of human beings come together to confront together the problems that they face together: in other words, as the domain, par excellence, of collective action. If there are, or can be, collective obligations, then these must surely constrain the ways in which we can act collectively. One might even suspect-though this is not a suggestion which I shall explore in any more detail here-that considerations about collective obligations might play a central role in demarcating the form that any legitimate form of political organisation ought to take.

The fact that-with one or two significant exceptions ${ }^{2}$ - the notion does not play such a role within analytic political philosophy might be explained in number of ways, only some of which would reflect well on that enterprise. One would be if the notion was not, in fact, coherent. If that were true the notion of collective obligation might still be one which played an important role in 
explaining people's beliefs and actions within the political sphere. It might also still be of some interest to political philosophers, who might legitimately concern themselves with trying to make sense of what people who relied on the notion took themselves to be saying, or with trying to tease out a rational core contained within the mystical shell of beliefs expressed in terms of that notion. Another would be if the notion, while coherent, was in some way less than fundamental: if, for example, the claim that some group had a collective responsibility was simply reducible-in some sense of that multifaceted philosophical word-to claims about individual obligations.

In this paper I argue that neither of these claims is correct. In particular, I argue for the existence of what I shall call 'genuinely collective obligations' and explore some of the relationships which exist between such obligations and the obligations which fall on individuals who make up those collectives. By a 'genuinely collective obligation' I mean an obligation whose subject or bearer is a group of individuals or a collective: one intended contrast here is with obligations which fall on individuals in virtue of their membership of a group or a collective. I shall call this latter kind of obligations 'membership obligations'.

While there is an important conceptual distinction between the two kinds of obligation, there are also important connections between them. One sort of connection whose existence I shall argue for is explanatory: we sometimes need to appeal to the existence of collective obligations in order to explain why individuals in particular situations have the obligations which they do. ${ }^{3}$ This explanatory connection is broadly epistemological in nature. It exists in virtue of a deeper, ontological connection: collective obligations often give rise to those individual obligations that their existence explains. These are two of the relationships between collective and individual obligations which my title mentions. The third relationship is supervenience: I shall argue that collective obligations supervene on individual obligations, in a way which I shall make more precise in due course.

The claims that I shall be putting forward about these relationships are independent of the argument that I use to defend the existence of collective obligations. While I take that argument to be a good one, someone who is persuaded of the existence of collective obligations on other grounds might nonetheless wish to endorse the claims I am making about the relationships between collective and individual obligations. These relationships between collective and individual obligations are interesting in their own right. Getting clear about them also helps us to get a better grip on whether the notion of a collective obligation is coherent, and on what things are and are not good reasons for believing or disbelieving in the existence of collective obligations as a class. It may also make us clearer about particular instances of collective obligation.

The claims I defend about the explanatory role of collective obligations also have a significant bearing debates between those who think that there are genuinely collective obligations, and those who do not. The explanatory role of collective obligations gives us one kind of reason for believing in the existence of particular collective obligations. An understanding of this explanatory role 
also helps to undermine some arguments against their existence. In particular, I shall argue in Section 8 that it undermines two different kinds of reductionist strategy: that of analytic reductionists, who hold that claims about collective obligations are simply equivalent to more complicated claims about sets of actual or possible individual obligations; and that of ontic reductionists who hold that whether or not claims about collective obligation are equivalent to claims about individual obligations, they are made true, when they are true, by facts about individual obligations.

One might think that even if claims about collective obligations cannot be reduced to claims about individual obligations, they do supervene on such claims. This suggestion is intuitively plausible. However it is rarely argued for in the literature. In Section $9 \mathrm{I}$ argue for it. If the conclusion of the argument is correct it might go some way towards explaining the widely felt sense that collective obligations are, in a certain sense, unreal. Nevertheless, if I am correct about the explanatory role of claims about collective obligations, it would do so without vindicating that sense. In explaining, without vindicating, one source of pressure towards viewing collective obligations as unreal, we gain greater clarity in what is at stake in debates over collective obligation.

In general, the supervenience of one set of claims on another set of claims does not guarantee the reducibility of the first set to the second set. This follows from the fact that reduction is an asymmetric relation-if As reduce to Bs, then Bs do not reduce to As-whereas supervenience is merely non-symmetric. However, there are domains where the idea that one set of claims might supervene on another without the second being reducible to the first has proved hard to defend. This is notoriously the case with the claim that the mental supervenes on, without being reducible to, the physical. ${ }^{4}$ In Section 10, I shall argue that the reasons we have for being suspicious of the possibility of supervenience without reduction in the mental/physical case do not carry over to the collective obligation/individual obligation case.

\section{Preliminaries: Terminological and Otherwise}

Where I speak of collective obligations, others might prefer to speak of collective responsibility. This may simply be a matter of terminology. But there are deeper conceptual issues in the vicinity. Obligation is primarily a forward-looking notion, whereas responsibility looks both forward and backwards: the domain of things that one can be obliged to do lies in the future, whereas one can be responsible for both events in the past and future outcomes. Furthermore, the notion of 'responsibility' is sometimes thought to bring with it a set of dense conceptual connections with notions of agency, autonomy, blame and so forth, which the notion of obligation may lack. ${ }^{5}$

The comparative conceptual richness of the notion of responsibility can be both an advantage and a disadvantage when it comes to defending positive claims about norms that bear on collectives. One advantage is that it suggests a 
possible strategy for arguing for such claims - that of showing that certain collectives meet certain criteria of agency, autonomy, or blameability and should thus be regarded as loci of responsibility. ${ }^{6}$ However it makes those normative claims hostage to a variety of intuitions that individuals may or may not share about the preconditions of agency, autonomy or blameability. My strategy for arguing for normative constraints on collectives does not depend on any advantages which use of the language of responsibility might bring, and is not subject to the disadvantages it brings with it. So my avoidance of that language is partly tactical: it allows me to remain relatively uncommitted about the metaphysics of collectives; and in what follows I shall commit myself as little as possible.

My views commit me to the existence of collectives. I take this commitment at face value. Furthermore, I take the class of collectives to be relatively inclusive, and to contain not only relatively richly structured groups with what Peter French has called a 'corporate decision structure', such as business entities, states, governments but also much looser and more informal groupings, such as the set of occupants of a given office, the inhabitants of a town, village or region, and the witnesses of the murder of Kitty Genovese. ${ }^{7}$

My choice of the language of 'collective obligation' over that of collective responsibility is not excluively tactical. It also reflects differences between the sorts of normative claim that I shall be focusing on in this paper, and the sorts of claim which are most often discussed by those whose primary interest is in collective responsibility. Such authors often focus on groups which have a complex-and sometimes highly formalised-decision structure. While studying the normative constraints to which such groups are subject can be extremely illuminating, one might feel that by focusing on complex cases rather than simple ones they approach some of the issues involved from the wrong direction. In any case, my focus will be different: I shall be particularly-but not exclusively-concerned with obligations which fall on relatively small, unstructured, and informal groups. This topic has been less well explored and is of at least equal interest. ${ }^{8}$ However, despite my interest in the obligations of relatively unstructured groups, I shall not be defending the implausible view that any collective whatsoever can be the subject of moral obligations. ${ }^{9}$

One final terminological issue needs to be addressed. Many authors distinguish - as I shall do at some points below-between all-out and pro tanto obligations. I understand this distinction as follows: an act which we have an 'all-out' obligation to perform is, simply, an action which, given the full normative and non-normative context, we must (morally) perform, while a pro tanto obligation is an obligation which can be outweighed by competing considerations of at least some kinds (including competing moral considerations). The distinction is typically applied to obligations which fall on individuals; but if collective obligations exist, we can draw a similar distinction between kinds of collective obligation. For example, one might think that in the absence of specific legislation, a business corporation has a pro tanto obligation to treat their employees according to certain norms of fairness, but that this obligation can be 
outweighed by other considerations, such as a fiduciary obligation to maximise the profits of shareholders. By contrast, the same corporation's obligation not to hire contract killers to eliminate the CEO's of its business rivals is not merely pro tanto but an all-out obligation..$^{10}$ Unless otherwise specified, the obligations discussed in Sections 3-7 should be taken to be pro tanto obligations.

\section{Moral Phenomenology}

In arguing for the existence of collective obligations I shall adopt the following strategy: I shall describe a fairly mundane situation (which I shall call 'Office') and I shall make a number of claims about what one might call the 'moral phenomenology' of the situation. In particular I shall claim that it is part of the moral phenomenology of the situation that there is a collective moral obligation, and that it has a particular explanatory significance. I shall then argue that we should take the moral phenomenology at face value.

As I shall explain in more detail in a moment, my use of the phrase 'moral phenomenology' will be somewhat non-standard. It is also worth emphasising that, in my usage, it is not simply synonymous with the notion of a moral intuition. ${ }^{11}$ For this reason, many of the objections which might be raised to the idea of appealing to intuition in this context do not seem to apply here; or at least, do not apply in an obvious manner. ${ }^{12}$ Nevertheless, philosophers who take appeals to intuition to be capable of providing some kind of legitimate justificatory role in ethics should feel comfortable with the role which I have given to moral phenomenology.

Here is a stipulative definition of the phrase 'the moral phenomenology of a situation'. It should be understood to cover the sorts of claims which a reasonably reflective intelligent, but philosophically incurious individual might appeal to in reflecting on or discussing what might need to be done in that situation. ${ }^{13}$ The fact that such a claim would be made by such an individual is a sufficient condition of its being part of the moral phenomenology, given the way in which I am using the phrase. (Notice that although I have defined the term 'the moral phenomenology' I shall neither define nor use the terms 'my moral phenomenology' 'your moral phenomenology', or 'John Smith's moral phenomenology'.)

'It is part of the moral phenomenology that...' is not a factive sentential operator. The moral phenomenology of a particular situation may not be consistent: there may be situations about which reflective individuals are tempted-either as individuals or collectively - to say inconsistent things about. In such cases, not everything that is part of the moral phenomenology of the situation can be true. And there may be other cases where what is part of the moral phenomenology does not correspond to what is actually the case, morally speaking.

We can intelligently disagree, and can intelligibly be wrong about what the moral phenomenology of a situation is. So the phrase 'It is part of the moral phenomenology that $\mathrm{p}$ ' is not simply a stylistic variant for 'It is my intuition that 
p. ${ }^{\prime 14,15}$ Whatever intuitions might be, the standard philosophical usage of the term intuition seems to leave no room for the idea that I might be wrong about what my intuitions are.

Since I am a professional philosopher, my intuition that $\mathrm{p}$ is at best good evidence for the fact that $p$ is part of the moral phenomenology: although I am, I hope, reasonably reflective, I am not philosophically incurious. Equally, your intuition that not-p is not conclusive evidence that not-p is part of the moral phenomenology. since you are presumably not philosophically incurious either. Moreover, your intuition that not-p is not particularly strong evidence that $p$ is not part of the moral phenomenology: the fact that you, a philosopher, would say that not-p is poor evidence that some other individual would not say that p. ${ }^{16}$ Notice that it is easier to establish that something is part of the moral phenomenology than that it is not-this explains the asymmetry here. ${ }^{17}$

Moral phenomenology plays - and should play-an important role in moral theorising. However, it is not clear exactly what role moral phenomenology it should play. Certainly, we should not expect moral theorising to vindicate the whole of the moral phenomenology of every situation. As I have noted, the moral phenomenology of a situation may be inconsistent. It may also be misleading. Since the reflective and philosophically incurious may be-like reflective and philosophically curious-morally corrupt, the moral phenomenology may include claims that, on reflection we should not endorse.

Here are two claims I endorse which are consistent with these melancholy reflections on the shortcomings of moral phenomenology.

M1) The defensibility of views which require large departures from the phenomenology of everyday situations depends on the availability of plausible explanations of how the phenomenology comes to be in error.

M2) It is a virtue of a view within theoretical ethics that it vindicate a large amount of the phenomenology of actual situations, and views which do so are to be preferred, ceteris paribus, to views which do not.

M1 should seem fairly uncontroversial: it says only that those who put forward views that reflective individuals find counter-intuitive owes us some explanation of why these people come to form views which are, by their lights, mistaken. This argumentative standard is widely accepted, even by those who are skeptical about the role of intuitions in ethics. ${ }^{18}$ Such skeptics normally take it to be incumbent upon them to give some sort of account of the ways in which people's moral intuitions are misleading.

While M2 is less obvious than M1, it is also widely accepted within much of analytic moral theory. ${ }^{19}$ To deny it is to claim that the fact that a moral view fails to fit with the moral judgments that people actually make does not count against it at all. This seems very implausible. In evaluating a moral theory we normally think that the fact that it goes against judgments that people would normally be inclined to make is a theoretical cost-one which may be outweighed by other benefits but a cost nevertheless. ${ }^{20}$ 
I have argued that M1 and M2 ought to seem uncontroversial. I have done so by claiming that in arguing, moral philosophers often appear to be making implicit appeal to principles of this sort. Still it is conceivable that M1 and M2 are nonetheless false. Their falsity would undermine some of the arguments that I put forward in Sections 4 and 5 of this paper (although they would leave much of what is said in Sections 6-10 intact). Their falsity would also undermine many other arguments within moral philosophy. If my arguments fail because of the falsity of M1 and M2, their failure results from being held to a higher standard than advocates of many other ethical views are held to. It is not obvious why a defense of collective obligations should be held to a higher standard than defenses of other ethical views.

I have emphasised some of the more significant ways in which the notion of 'moral phenomenology' which I have been relying on differs from the notion of an intuition. However to the extent that appeals to intuition are intended to play a justificatory role within ethics, what we typically find are appeals to 'shared' (or even 'widely shared' intuitions) about particular cases. Intuitions which are 'shared' in the relevant sense are surely not ones which the authors appealing to them take to be shared only by their philosophical colleagues. The sharedness of such intuitions would surely carry little justificatory weight. So the intuitions which are being appealed to in this context are ones which are likely to be ones which form at least a part of the moral phenomenology of the situation. If so, then philosophers who are comfortable with appeals to intuition should also endorse my appeals to moral phenomenology.

One might object that moral phenomenology can be vague, unreliable and inconsistent. I agree. However, M1 and M2 do not entail the opposite. Nor should we think that the fact that moral phenomenology is vague, and sometimes unreliable and inconsistent is a reason for according it no role in our moral theorising. Perceptual judgments can be vague, unreliable and inconsistent: no-one thinks they should play no role in our theorising.

Some may hold that M1 and M2 give too significant a role to the judgments of non-experts: they would prefer principles which require not that the views of philosophers, rather than the views of the reflective but unphilosophical be either vindicated or explained. (Perhaps they think that when Aristotle appeals to the views of 'the many and the wise', he should have ignored 'the many'.) I disagree. If M1 and M2 entailed that the views of philosophers should be given no weight, they would be implausible. However, they do not entail this. Furthermore, while it seems implausible that the views of philosophers should carry no evidential weight, it seems just as implausible that this should be true of the ethical views of the reflective but non-philosophical. If it were, it would be mysterious how anyone-even philosophers-should have acquired ethical expertise. For philosophers typically acquire at least some parts of their ethical outlooks from others, and those others are most often not philosophers themselves. But if those views carry some evidential weight and it is not the weight that M1 and M2 suggest they should carry then it is not clear what it is.

(c) 2014 John Wiley \& Sons Ltd 
Timothy Williamson has argued that appeals to intuition within philosophy often involve an undue psychologisation of the philosophical evidence base. ${ }^{21}$ It is typically not one's intuition that something is the case that provides evidence for a philosophical claim, but the fact that that thing is so. According to Williamson, this psychologisation of the evidence base involves a response to a potentially all-encompassing skepticism about philosophical knowledge claims which is both unduly concessive and also doomed to failure. Although I have argued that on my usage 'phenomenology' is not a synonym for 'intuition', one might wonder whether my appeal to phenomenology also involves inappropriate psychologisation of the evidence base. It does not. One reason why one might find M1 and M2 attractive is that one thinks that reflective but non-philosophical individuals have at least some moral knowledge about reasonably commonplace situations. M1 and M2 allow one to appeal to this fact without specifying at the level of principle exactly what these individuals know. This reason for endorsing M1 and M2 involves no concession to skepticism of any sort.

\section{An Example}

Let us now consider a situation in which it seems appropriate to talk of collective obligations. As a matter of deliberate expository choice, it is conspicuously mundane. ${ }^{22}$

Office: Two people share an office. Due to bad weather the roof starts to collapse. The person who needs to be informed has to be informed by email. A has the technical expertise necessary to describe the damage to the roof in an informative manner, but doesn't know how to use email. $\mathrm{B}$ is a computer wizard who doesn't know the first thing about roofs. Between them, they can pass an informative message to the right person. Individually, neither of them can. ${ }^{23}$

In Office, a group of individuals can achieve significantly more by collaborating in an intelligent manner than they can by means of their own unaided efforts. This may or may not be obvious to those individuals. Nor need it be obvious to them how exactly they will need to collaborate in order to solve their problem.

That much should be uncontroversial. The following claim, which I wish to defend, is not: A and B fall under a collective obligation to inform a responsible person about the state of the roof before a passer-by is injured. On my use of the phrase 'collective obligation', this claim is to be glossed in the following way: there is an obligation which falls neither on A nor on B but on a collective consisting of A and B, or, as I shall sometimes say, of which A and B are members. As we shall see, the existence of this collective obligation does not preclude the existence of obligations which fall on A and B individually: in fact, it gives rise to such obligations.

The collective obligation can be discharged (collectively) if $\mathrm{A}$ and $\mathrm{B}$ co-ordinate their efforts in a suitable manner: A dictates the text of an email to 
$B$ and $B$ sends the email. If $A$ and $B$ act in this way they will have done what they ought, collectively, to have done. If not they will have failed to do so.

To discharge the collective obligation which falls on them, A and B each need to perform a number of different actions. For example, A needs to tell $\mathrm{B}$ what needs to be said in the email; $\mathrm{B}$ needs to type it into the computer and press 'send' and so on. As well as holding that 1) A and B together have a collective obligation to inform the relevant individual about the state of the roof, I take it that 2) each of A and B have individual obligations to perform the actions they need to perform in order to see to it that that individual is informed; 3 ) these obligations arise out of the collective obligation under which they fall and that 4) the existence of the collective obligation, together with some facts about the world-such as facts about the respective capacities of A and B explains the existence of the particular obligations which A and B have.

I also take the following to be true

PC) the truth of 1)-4) forms part of the 'moral phenomenology' of Office.

On my use of the term 'moral phenomenology', claims about what is and what is not part of the moral phenomenology are not luminous and selfvalidating. They can be supported by argument. and I shall provide some argument for PC. In Section 5 I shall argue that 3 and 4 are part of the moral phenomenology. Those who are skeptical as to whether 3) and 4) could possibly be part of the moral phenomenology are asked to keep their skepticism in check until then.

M1, M2 and PC together entail that we have good, though defeasible, reason for holding that collective obligations form part of the moral landscape which needs to be negotiated by A and B in 'Office', and more generally that collective obligations exist. For M1 and M2 give us reason to think that a good theoretical view in ethics ought to vindicate the truth of the package of claims in PC.

Despite being mundane, Office illustrates a phenomenon which is quite common, and which has many more consequential instances. Other situations in which one might think that collective obligations exist, give rise to, and explain the obligations of individuals include the obligations that partnered parents have to see to the upbringing and welfare of their young children; the obligation of a group of siblings to provide for the care of an aging parent; obligations on the citizens of a nation defeated in war who no longer have a functioning political system to institute such a system in order to bring to justice the perpetrators of crimes against humanity; and the obligation on the part of the world's population as a whole to see to it that the world's economic system is organised in a way which enables the basic needs of all citizens to be met. ${ }^{24}$

\section{Laying Out the Phenomena}

Since reasonable individuals can differ about the moral phenomenology of particular situations, a sincere assertion that 1)-4) constitute part of the phe- 
nomenology of 'Office' does not establish that they do. However, I suspect that few would dispute the claim that 2), at least, is part of the moral phenomenology here. Those who do need more than merely philosophical enlightenment. Most of us simply do take it to be the case that we have some kind of responsibility to prevent avoidable harm coming to others in situations where this requires little more than trivial exertion.

Given that it is part of the moral phenomenology that A and B have a number of individual obligations in a situation like this, we might go on to ask why these individuals have these particular obligations. This question could be purely theoretical. However, it might also arise within everyday practical discourse. For, although I have suggested that it is part of the phenomenology of a situation like 'Office' that A and B have certain obligations, it does not follow that the existence of this obligation must present itself to the individuals in question as being luminous and self-validating (although when all is going smoothly from a moral point of view, it may do so).

Consider a situation where A needs to overcome some kind of moral or personal aversion to B in order to be able to collaborate with them. For example, suppose B is an adulterer, a malicious gossip or a convicted criminal and A has purportedly moral scruples about engaging in co-operative action with people of this sort. A might well ask themselves if they were really obliged to do something as distasteful as co-operating with B. On entertaining the thought that they were, they might well ask themselves why. One natural answer might run like this: 'Well, whatever my feelings about B, like it or not, we're in this situation together, so we'd better try to do something about it. And, given our respective capacities, neither of us can solve this problem on our own. So I'd better speak to B and come up with a plan, no matter how distasteful that might seem.' The same line of thought might also be appropriate in contexts of admonition, advice-giving, or self-justification. Furthermore, it is a line of thought whose intelligibility, formulability and plausibility is not dependent on one's being possessed of philosophical curiosity. ${ }^{25}$ If so, then, given the way I have been using the term moral phenomenology it follows that the claim that there is a collective obligation which explains the individual obligations of $\mathrm{A}$ and $\mathrm{B}$ is indeed part of the 'moral phenomenology' of situations like 'Office'. And, given that the non-existent cannot explain the existent, this also suggests that the claim that A and B are under a collective obligation is also part of the moral phenomenology. ${ }^{26}$

What about the claim that the individual obligations of $\mathrm{A}$ and $\mathrm{B}$ arise out of their collective obligation? If this is part of the moral phenomenology, then it suggests that it is also part of the phenomenology that collective obligations can sometimes be more basic than individual obligations. This idea seems closely related to the claim that the existence of the collective obligation explains the existence of the individual obligation. Nevertheless it does not simply follow from that claim. As van Fraassen's notorious 'parable of the shadow' shows, the existence of one thing (a shadow of a certain length) can sometimes explain the existence of something ontologically more basic (the existence of a flagpole that casts that shadow). ${ }^{27}$ 
Nevertheless the claim that collective obligation gives rise to, and is thus more basic than the individual obligation can be defended along the following lines. Consider Office*, a situation just like Office except for the fact that A in Office* has the capacities and limitations of B in Office, and vice versa. It seems plausible that in Office*, A and B would have exactly the same collective obligations as in Office; but that their individual obligations would be reversed along with their capacities. But this is tantamount to saying that in Office* the individual obligations which exist in Office would not exist, (although other individual obligations would) even though the very same collective obligation would. This seems to establish both that the collective obligation is more basic (since it can exist without any particular set of individual obligations existing) and that, given further facts about the world-facts about the respective capacities of A and $\mathrm{B}$ - it gives rise to the individual obligations which $\mathrm{A}$ and $\mathrm{B}$ have.

This argument relies on the supposition that particular obligations have their bearers essentially-in other words that is a mistake to say, about Office*, that the very same individual obligations exist as in Office. If this was not a mistake, then one might hold that the possibility of Office* does not establish that collective obligations of $\mathrm{A}$ and $\mathrm{B}$ can be ontologically prior to the particular individual obligations of A and B, since in Office the very same obligations exist as in Office, but differently distributed. But it is a mistake. It is true that we sometimes speak of two people having the same obligation: for example, we might say that all the students in a class have the same obligation to submit their paper punctually. We would mean by this that they are all obliged to do the same thing-namely submit their paper on time. Nevertheless, the sadly familiar fact that some individuals might discharge his obligation while others do not, and that no-one could discharge it for another person by submitting their own paper on time-shows that there is another way of individuating obligations (as there is of individuating actions) on which the obligation bearer is essential to the identity of the obligation. It is this way of individuating obligations which I am interested in here. ${ }^{28}$

Some might suggest that it is part of the moral phenomenology that there are no obligations that fall on A and B collectively. I find this claim implausiblethough since, as I have already pointed out, there is no guarantee that moral phenomenology is consistent, I cannot simply rule it out on the basis of what has been said so far. Admittedly, philosophers might hold that there are no collective obligations. For reasons given in Section 3, that is weak evidence for the claim that their existence forms no part of the moral phenomenology of Office. Hostility on the part of analytic philosophers to the idea of a collective obligation may stem from an underlying-but perhaps unarticulated-propensity towards individualism in social philosophy. It is not obvious that such hostility is to be found among the philosophically incurious. But if one thought it was, and that this would lead reflective but unphilosophical individuals to claim there were no collective obligations in Office, then the defender of collective obligations would need to explain why people should make this claim. The natural answer would be that they do because they are wrongly persuaded that there are no collective entities for them to fall on. 


\section{Redescribing the Phenomenology}

I have argued that claims 1)-4) are part of the phenomenology of situations like 'Office', and that this gives us good, but defeasible reason for holding that collective obligations exist. One might object either by claiming that I have misdescribed the phenomenology or by arguing that in this case we should not take the phenomenology at face value.

Consider the first possibility. The objector who takes this line needs to provide an account of the phenomenology of Office which accepts 2) (which seems non-negotiable) while avoiding 1),3) and 4). One such account is this: there is a morally primitive obligation on individuals faced with the possibility of harms to others which they cannot individually prevent to engage in a suitable co-operative scheme to prevent those harms. ${ }^{29}$

In the light of M1 and M2 someone who thinks like this should also be prepared to try to explain why 1), 3) and 4) seem appealing. This seems hard. One might attribute some form of institution worship to those who accept them. ${ }^{30}$ However, the informal and unstructured nature of the group involved in Office makes this charge seem implausible here.

The 'primitive obligation to co-operate' account of the phenomenology of 'Office' might seem simpler than the account I advocate, because it is only committed to the existence of one kind of obligation-namely obligations on individuals. Simplicity is certainly an important theoretical virtue. However, it is not obvious that it is a desideratum in phenomenological description. One might even take a preference for simple accounts of the phenomenology of complex situations to be a mark of an impoverished moral sensibility.

The appeal to simplicity is inconclusive: it would be difficult to arrive at a well-founded judgment of the comparative simplicity of the two theories on offer here without seeing them both worked out in detail. ${ }^{31}$ Still, we should notice that is is not clear that collective obligations are a distinct kind of obligation, rather than a familiar kind of obligation falling on a new kind of thing. ${ }^{32}$ (It would not count against a theory's simplicity that it attributed obligations to silicon-based Martians, as well as to human-beings, if we found human-like intelligence on Mars.) Furthermore, even if we concede that there are two kinds of obligation here, the collective obligation account appears to gain some ground on the primitive obligation account, by giving us a more unified picture of the moral scene, since it postulates one underlying obligation which explains a range of individual obligations, rather than a large number of unconnected primitive obligations.

Moreover, the 'primitive obligation to co-operate' account seems to get the phenomenology of situations like 'Office' backwards. Presented with such a situation it would be somewhat unnatural to start off by thinking: 'Here's a problem-now I've got to find someone to help me with this' and then search for suitable candidates. To do so would be slightly pathological-the response of someone who finds it unnatural to regard a problem as being in the first instance, a problem which a group of individuals face together. (There may be 
some situations which called for collective action but in which this kind of 'alienated' response is understandable, and even appropriate. However, in the absence of further elaboration Office doesn't seem to be one of them.)

The idea that the existence of a collective obligation is part of the phenomenology of Office might be bolstered by thinking of other kinds of groups than the relatively informal group in 'Office', and especially groups with which individuals often identify, such as families and-perhaps-nations. Consider for example, a situation in which parents share responsibility for a child or grown-up siblings for an elderly parent. An account of their situation which spoke only of their individual obligations but which made no reference to the ways in which their situation was shared might seems to miss an important part of the moral landscape.

\section{Challenging the Phenomenology}

I have argued that we have good, but defeasible, reason to take the phenomenology of Office at face value. I have also argued that the 'collective obligation' account of the phenomenology should be preferred to the 'primitive obligation to co-operate' view. If so, we have good but defeasible reason to think there are collective obligations. One might nonetheless object that the existence of collective obligations entails the existence of collectives and deny that collectives exist. Since I take flat-out denials of the existence of collectives to be extremely implausible, I shall not discuss this objection any further. ${ }^{33}$

A more interesting objection is that my view commits me to an extravagant view of the scope of collective agency. Nothing I have said places any limits on the class of collectives which can be subjects of obligation. But since obligations are obligations to act, one might think that only agents can be the subject of obligations. Nevertheless, it is at least plausible that the class of collectives that are agents is narrower than the class of collectives tout court. For example, one might well hold that there is a collective whose members are all and only Peter van Inwagen, Zinedine Zidane, and my seven-year-old son, while denying that this collective was in any sense capable of agency. So my view would appear to allow the possibility of obligations falling on non-agents.

This objection is fallacious. Its apparent plausibility depends upon ignoring a distinction between those collectives that actually are agents and those that are capable of becoming agents-what we might call 'potential agents'. The fact that obligations are obligations to act only entails (in conjunction with the premises that 'ought implies can') that the subjects of obligation should be capable of action, not that they actually be agents. Potential agents are capable of action in what I take to be the appropriate sense of capability here. My view is that only those collectives that are capable of becoming agents can be subject to obligations. However, I also hold that the boundaries of the class of potential agents is fairly large, and certainly wide enough to hold a collective consisting of A and B from 'Office'. 
It is worth emphasising here that the view that I am defending is one on which collectives which are not agents but which have the potential for agency, can be the subjects of actual, and not merely potential obligations. This will be significant in what follows, since I will be appealing to the role which collective obligations can play in explaining the obligations of individuals in order to resist arguments for various kinds of reductionism about collective obligation. It is not clear that we could appeal in the same way to potential obligations of collectives to explain the actual obligations of individuals. ${ }^{34}$

\section{Reductionist Concerns}

One might agree with everything that has been said so far in defense of the view that collective obligations exist, but still hold that such obligations are, in some sense, reducible to individual obligations. However, reductionism is implausible if some of my claims about the explanation are accepted.

First, distinguish between two kinds of reductionist. Analytic reductionists hold that claims about collective obligations have the same meaning as more complex conjunctions of claims about individual obligations (perhaps including counterfactual conditional claims about what obligations individuals would have under non-actual circumstances.) Ontic reductionists make no claims about translatability: they hold only that claims about collective obligations are made true by facts about individual obligation. Both forms of reductionism are undermined by the fact that in many cases the sorts of individual obligations to which both sorts of reductionist appeal arise out of, and are explained by the existence of collective obligations. ${ }^{35}$

To see why, it is worth drawing an analogy with a similar line of argument in the philosophy of mind. It is frequently held that analytic behaviourism is refuted by the fact that the sorts of claims about action which purportedly reduce our talk about mental states are in fact to be explained by reference to those mental states. If analytic behaviourism were correct, such explanations would be vacuous - and their vacuity should be apparent to anyone with a grasp of mental state terms. Since they are not, analytical behaviourism is untenable. ${ }^{36}$

Explanations of individual obligations by reference to individual's membership of a collective and to the obligations of a collective they belong to are no more vacuous than explanations of the behaviour of individuals by reference to their mental states. Consider 'Office' again. I have argued that it is part of the moral phenomenology that the individual obligations of $\mathrm{A}$ and $\mathrm{B}$ can be explained by reference to the existence of a collective obligation and by $\mathrm{A}$ and B's membership of the relevant collective. I also argued that in some cases we might justify a claim about an individuals obligations by reference to the collective obligations. If explanations of individual obligations by reference to collective obligations were vacuous, then it is hard to see how the appeal to a collective obligation could justify here.

One could deny that we have a non-vacuous explanation here. One reason for doing so might be that 'Office' seems to be a situation where it is obvious what 
the obligations of $\mathrm{A}$ and $\mathrm{B}$ are-and perhaps less obvious what the obligations of the collective are (though I dispute that this is, in fact, unobvious). The objection appears to rely either on the principle that there cannot be a substantive explanation of something obvious; or on the principle that what is unobvious cannot provide a substantive explanation of what is obvious. Neither principle has merit. It is-hopefully-obvious that one should not murder; but different moral theories explain this obligation in different ways-one saying that there is a divine command to do no murder, another saying that a prohibition on murder is part of a utility-maximising set of rules-and so on. (Since these theories are less obvious than the wrongness of murder, they might not be able to justify a belief that murder is wrong: that is a different matter.)

If the obligations involved in Office seems obvious, this is because I have concentrated on a simple case for expository reasons. Many cases are less straightforward. Consider parental responsibilities. In some situations it may make sense to say of a couple with a newly born child that-perhaps within certain limits - the two of them have a collective obligation to provide for the well-being and education of the child. Various individual obligations may arise out of this; and while it may be obvious in some cases and in some situations what these obligations are and on which parent they fall, this will not always be the case, especially when unforeseen events occur. Like 'Office' this case involves a group which is relatively small and which has little internal formal structure, although it differs from 'Office' insofar as it involves two individuals who have an obligation which is both long-term and open-ended.

Another kind of case is provided by the inhabitants of Germany after 1945, after the defeat of the Nazis. One might think that even in the absence of a properly functioning political system-and thus of anything corresponding to a 'corporate decision structure', this group of individuals stood under an obligation to institute some such sytem, to organise themselves in such a way as to be able to try and punish prominent Nazis. It is plausible that a collective obligation of this sort would also give rise to obligations on the part of many of the individuals who formed part of this group and that it might intially be far from obvious which obligations fell on which individuals. ${ }^{37}$

So much for analytic reductionism. What about ontic reductionism? Ontic reductionists hold that whether or not statements about collective obligations can be translated without loss of meaning into talk about individual obligations, such statements are nonetheless made true by facts about individual obligations. This seems incompatible with the idea that, in situations like 'Office' individual obligations arise out of collective obligations rather than vice versa. If there were no self-standing facts about collective obligations, and true claims about such obligations were made true by truth-makers for truths about individual obligations, then we could not hold that the truths of any claims about individual obligations arose from the truth of claims about collective obligations. For the former would not be distinct from the latter; and a claim of priority (which the claim 4 seems to be) must surely entail a claim of distinctness. So, since (as I have 
argued) we have reason to accept the claim that in Office, collective obligations are prior, we also have reason to deny that ontic reduction is a possibility.

These points do not refute a view we might call 'Necessary and Sufficientarianism' or NAS: the view that any statement about collective obligations has metaphysically necessary and sufficient conditions which can be stated in terms of individual obligations. ${ }^{38}$ However NAS is not, as it stands, a reductionist view. It simply asserts the existence of a set of metaphysically necessary biconditionals without making any claims as to whether one side of the biconditional should be regarded as more basic than the other. Reductionism of any sort require some kind of priority claim.

NAS only provides grounds for reductionism if there is some reason for taking the side of the metaphysically necessary biconditional which it asserts to exist for each statement about individual obligations to be more basic than the side which talks about collective obligations. If, in cases like Office, claims about collective obligation are explanatorily prior to claims about individual obligations we are unlikely to find such reasons.

One might object that individual obligations must be more basic, since it seems clear that there could be worlds in which there are individual obligations but no collective obligations, but if NAS is true the reverse is not true. However, this is not enough to justify an inference from NAS to a form of reductionism. What the reductionist needs to show is that, in a case where a collective obligation exists and hence (because NAS is true) some individual obligations must also exist, the particular individual obligations whose existence is guaranteed by $N A S$ in this situation are more basic than the collective obligation in question. This does not follow from the fact that there are some individual obligations that could exist without collective obligations existing. And, furthermore, the fact that the existence of some of these individual obligations is not merely guaranteed by the collective obligation, in the sense of being a sufficient condition for them to exist, but is actually explained by them suggests that these obligations are not more basic in any sense that is likely to be of interest to the reductionist.

\section{Collective Obligations and Supervenience}

Many philosophers may still feel that collective obligations are in some, yet-to-be -explicated way, unreal. I disagree. I shall now argue for a claim about the relationship between individual and collective obligations which may explainbut does not justify - a belief that collective obligations are unreal and which is of non-negligible independent interest. The claim is that collective obligations supervene on individual obligations.

This claim is imprecisely stated. Here is a more precise formulation: there cannot be a difference in the distribution of all-out collective obligations between two possible worlds without there being a difference in either the all-out or the pro tanto obligations of individuals. This is a claim involving what is known as global supervenience, formulated in terms of possible worlds. (My choice of a 
formulations of this global supervenience claim in terms of possible worlds rather than one expressed in terms of modal operators should be regarded as expressing an expository rather than a substantive preference.) The distinction between all-out and pro tanto obligations is important here because my argument will rely on a claim about the relation between collective and individual obligations whose equivalent, formulated just in terms of all-out obligations has been subjected to devastating attack by David Copp. The claim on whose truth I shall be relying escapes his objections. ${ }^{39}$

My argument depends on two highly plausible claims. One is that the facts about collective actions supervene, globally, on the facts about individual action. ${ }^{40}$ If they did not do so, collective action would be highly mysterious. İt would be difficult to see what could make it the case that a collective had acted one way rather than another if it was not an action on the part of some individual or group of individuals. Furthermore, if collective actions do not have mysterious, emergent causal powers of their own-which seems highly implausible, and if they are not causally isolated-which would make our knowledge of them mysterious, than it seems as though they could only have the causal powers they have in virtue of the causal powers of something else-namely, the individuals that make them up.

The second claim the argument depends on is that all-out collective obligations entail, but are not equivalent to, certain pro tanto conditional obligations on the parts of the individuals who make up the collective. If in a particular situation a collective $C$ has an all-out obligation to Phi, then, for any member $M$ of $C$, and for any set $S$ of possible actions of members of $C$ that, if performed together, would constitute C's Phi-ing, if S includes M's doing $A$, then $M$ has a pro tanto obligation to do A provided that (a) the other members of $\mathrm{C}$ are doing or are reasonably likely to do the actions assigned to them in $S$ or they would be reasonably likely to do these things if $M$ were to do A and (b) M's doing $A$ does not by itself make it less likely that $\mathrm{C}$ will Phi.

I shall argue for this principle in a moment. But notice first that the view about supervenience that I am defending follows from these two claims. For a change in collective obligations entails a change in the sets of collective actions which need to be performed if a given collective is to fulfil its obligations. But since collectives can only act via the actions of the individuals who make them up, this entails a change in the ways in which individuals can act to fulfil those obligations. But, by the second principle, if the set of ways in which individuals can act so as to fulfil their collective obligations changes, so does the set of individual obligations. So any difference in all-out collective obligations in a particular situation involves a difference in individual obligations, although the difference may be one in either all-out or pro tanto obligations.

One might think that we could argue for a principle similar to the one I have suggested, but linking all-out collective obligations to all-out individual obligations, since if some such principle were not true, there would be situations in which all individual obligations were met, and in which some collective obligations remained unmet. At first sight this seems absurd, since collectives can 
only act via the actions of individuals. Nevertheless, David Copp argues that cases of this sort can occur: for example, a committee may fail to carry out its obligations even though none of the individuals on it fail to carry out their obligations. ${ }^{41}$

It is harder to devise cases which constitute a counter-example to the principle about pro tanto obligations. Copp's cases involve situations where the obligations of a collective body impose pro tanto obligations on its members, and these pro tanto obligations are themselves defeated by countervailing obligations. In general, we do not say that when a pro tanto obligation is defeated by some countervailing consideration that that obligation no longer exists; merely that in this particular situation it does not yield an all-out obligation.

Here is an argument for the principle about pro tanto obligations, based on a broadly Kantian account of morality. It starts from one of Kant's formulations of the categorical imperative-the formula of the kingdom of ends. Kant argues that any rational being should will as if they were the legislator for a kingdom of ends. ${ }^{42}$ One plausible suggestion as to what Kant means by this is that a kingdom of ends is, among other things, a state of affairs where all rational beings are treated as ends-in-themselves. But such a state of affairs is presumably also one in which everyone fulfils all of their obligations (since Kant also seems to hold that all of our duties can be derived from a duty to treat rational beings as ends in themselves). If we are good Kantians, then the scope of the universal quantifier here is not simply the class of human beings, for Kant thinks that moral laws apply to all rational beings. One might think, as an alternative, that it ranges over all individual rational agents. But if the class of obligation holders is wider than the class of individual rational agents-as I have argued it is-it is hard to see why the quantifier in the suggestion should not range over all obligation bearers.

Kant also holds that 'whoever wills the end wills wills also the means that are indispensably necessary to his action. ${ }^{\prime 3}$ So, if there are collective obligations, and a legislator in a kingdom of ends necessarily wills that all obligations-including collective obligations-should be satisfied (as I have suggested), then such a legislator in a kingdom of ends wills the necessary means for satisfying collective obligations be satisfied. However, as I have already argued, the only means by which collective obligations can be carried out is through individual action. So a legislator in a kingdom of ends will will that individuals act in such a way as to enable the obligations of the collectives of which they are members to be carried out.

This establishes something very close to the conclusion that we want to reach. For, on a Kantian view, the moral law is given by the content of what a legislator in a kingdom of ends would will. So if we have established that a universal legislator would will that individuals act in such a way as to allow collective obligations to be carried out by means of their concerted efforts, then we have established that there are moral obligations on individuals of the sort that I have been arguing for. However, there is one loose end to tie up. For, while the thesis that I have been defending makes reference to the notion of a pro tanto 
obligation, the argument that I have given does not involve this idea. In fact one might even suspect that the notion of a pro tanto obligation is so profoundly unKantian that ones chances of being able to argue for a thesis about pro tanto obligations along Kantian lines are very small indeed.

My response has two parts. One involves appealing to the intuitive plausibility of the notion of a pro tanto duty. For the purposes of my argument, we need the notion of a pro tanto obligation in order to allow for the possibility that moral claims that fall on an individual in virtue of their membership of some collective can be over-ridden by other, countervailing claims on them, while still leaving some form of moral residue. But the notion of a pro tanto duty is likely to play a significant role in any theory that allows for the existence of competing moral claims. A theory which makes no room for such a possibility runs the serious risk of assigning a set of obligations to an individual with the property that although he or she is capable of satisfying each of them individually, he or she is not capable of satisfying them all at once. This should seem highly unsatisfactory to anyone who is impressed by the thought that 'ought implies can' (and a fortiori to any Kantian).

This point may settle matters for some readers. Others may object that, although a notion of this sort might be highly desirable in a moral system, it is unlikely to be available to anyone with Kantian sympathies. I disagree, although my case for doing so is somewhat speculative. For Kant's thinking clearly and explicitly makes room for a distinction between perfect and imperfect duties, and while the notion of an imperfect duty does not line up exactly with the notion of a pro tanto duty that I am appealing to here, it provides us with something that should motivate us to take that notion seriously. A key part of the notion of an imperfect duty, as Kant understands it is that while the moral claim that imperfect duties make on us is not in any sense optional, we have considerable discretion as to how exactly we are to comply with them. On any plausible account, part of that discretion must involve the permissibility of assigning such duties varying weights in deliberation in any concrete situation, while not allowing their moral force to be abrogated. (There may be some limits on what kind of variability is permissible here: presumably one is not permitted, on Kant's view, always to assign a certain kind of duty no weight whatsoever.) But the idea of a duty that may retain some claim us while being outweighed in certain contexts of deliberation simply is the notion of a pro tanto duty. So good Kantians ought to recognise this notion. ${ }^{44}$

\section{Supervenience without Reduction: Some Objections}

Claims about supervenience without reducibility in other areas of philosophy have often proved hard to defend. For example, the idea that mental states supervene on physical states without being reducible to them is sometimes thought to be vulnerable to devastating objections. Are there parallel objections to the view that collective obligations supervene on individual obligations without being reducible to them? I think not. 
One important argument against supervenience without reducibility in the mental/physical case is that the only empirical evidence we could have for the supervenience of the mental on the physical would also be evidence for the reducibility of the mental to the physical. Since my case for the supervenience of collective on individual obligations rests on conceptual rather than empirical grounds, there is no analogous objection here: questions about evidence are irrelevent here.

A second argument aims to undermine claims about supervenience without reduction based on the idea of mental properties being multiply realised by different configurations of physical properties, by appealing to the possibility of domain-specific reductions. ${ }^{45}$ Since my arguments for the supervenience of global on individual obligations make no explicit appeal to the idea of multiple reducibility, it also seems unlikely that a parallel argument can be constructed here either.

A third worry about the idea that the mental supervenes on the physical without reducing to it, is that standard versions of the view seem to run the risk of either making the mental epiphenomenal, or conflicting with the causal closure of the physical. Such arguments take the causal role of mental states to be incontrovertible. There are no similarly incontrovertible facts about the causal role of either collective or individual obligations. Obligations themselves, of whatever sort, are causally inert. ${ }^{46}$ (I have argued that facts about collective obligation sometimes explain facts about individual obligation. However, this sort of explanation is not causal explanation.)

Alan Carter has raised a further objection. ${ }^{47}$ He suggests that in thinking about the notion of institutional responsibility, we might want to allow for the idea of an institution taking on certain obligations while leaving it indeterminate which individuals in the institution are to be responsible for seeing that these obligations are adequately fulfilled. Questions about how an institutional obligation is to be fulfilled may then arise at some future time, and be settled on a more or less ad hoc basis; furthermore, these questions might remain unsettled, or find themselves settled in different ways depending on the vagaries of (non-moral) circumstances. These points might suggest that an institution can acquire an obligation without any of its members acquiring obligations. If so, then there can be pairs of worlds in which the distribution of collective obligations differs without the distribution of individual obligations changing.

One might object that such institutions are to that extent morally imperfect. Arguably, though, institutions have no practical choice but to behave like this. Perhaps in such cases, some individual or individuals at least acquire an obligation to consider how the obligations acquired by the group are to be carried out. ${ }^{48}$ If so, then Carter's objection fails. Still, it seems hard to rule out the possibility that a question about how an institution's responsibilities are to be discharged might sometimes legitimaately receive the answer 'In a few year's time we'll need to think about this. But nobody needs to worry about it right now'.

While I agree with Carter about the way institutions do (and, on his view should) behave, I do not think they show that the supervenience claim is false. 
Certainly, institutions take on obligations and only subsequently determine how those obligations are to be carried out. But much depends on what 'determination' involves. On Carter's view determination seems to involve creating individual responsibilities in the process of assigning them. An alternative view is that the process of determination involves two things: first, a process of working out what individual obligations have been created by undertaking collective obligations and second (in cases where these obligations are disjunctive, hedged or conditional in form), making decisions about how individuals are going to act to satisfy them.

On this view, the situation in which an institution acquires obligations without determining who is to carry them out can be understood in one of two ways. It may be a situation in which the individuals who make up the institution have acquired some determinate obligations and need to figure out what they are (so that there is some epistemic indeterminacy which needs to be resolved but no ontological indeterminacy). Alternatively it may be a situation in which, when the institution acquires an obligation a group of individuals acquires a set of hedged and conditional obligations, which they then need to make some decisions about. The appearance that when the institution has acquired obligations no individual has acquired obligations is an illusion, but one which may seem tempting if, as will often be true, no single individual has acquired an obvious all-out obligation to do some particular thing.

\title{
11. Conclusion
}

I have argued that in order to account for the moral phenomenology of some relatively mundane practical situations, we need to appeal to the existence of collective obligations; and I have argued that their role in accounting for this phenomenology provides us with good reasons for thinkin that there are such obligations. I have also argued that the role such obligations play in explaining the obligations of individuals counts against the plausibility of reductive accounts of collective obligation. Finally, I have provided an argument for the claim that collective obligations supervene on the obligations of individuals and explained why arguments from supervenience to reducibility in other domains do not have analogues here. In doing so, I take myself to have done some of the groundwork which is necessary for restoring the notion of collective obligation to a prominent place in political philosophy. ${ }^{49}$

\author{
Bill Wringe \\ Department of Philosophy \\ Bilkent University \\ Ankara \\ Turkey \\ billwringesemail@gmail.com
}

(c) 2014 John Wiley \& Sons Ltd 


\section{NOTES}

Earlier versions of this paper were presented in the contributed papers section at the Joint Session of the Aristotelian Society/Mind Association Southampton 2006, CollInt V in Helsinki, August 2006, a conference on Kantian Approaches to Ethics at Boğaziçi University organised by Lucas Thorpe and departmental seminars at Oxford Brookes University and the University of Keele and to an informal Work In Progress seminar in the Philosophy department at Bilkent University. I am grateful to audiences on all those occasions.

${ }^{1}$ For the suggestion that this may not be the only, or even the best way to approach issues in political philosophy see Geuss 2010.

2 These include Gilbert 2008 and Isaacs 2011.

${ }^{3}$ I use this word in the rough-and-ready sense with which it is used in everyday English, and not the technical sense it bears in some parts of philosophy of language. I thank my colleague Sandy Berkovski for urging this clarification.

${ }^{4}$ For examples of such reasons, discussed in more detail in Section 10, see Kim 1993.

${ }^{5}$ Pettit 2007. Of course, the notion of obligation does not float entirely free of conceptual connections: the thesis that 'ought implies can', on which I shall rely later codifies one such. What matters here is that the notion of obligation is thinner than at least some conceptions of responsibility.

6 Tollefsen 2003, 2006.

7 French 1984.

${ }^{8}$ One author who has discussed the obligations of unstructured collectives is Tracy Isaacs (Isaacs 2011: 23-70) who argues that both structured and unstructured, goaloriented collectives can be the subjects of moral obligation. One significant difference between our views is that she holds that collectives can only be the subjects of obligation if they are agents whereas I do not. See Section 7 for further brief discussion and Wringe 2010 for a full-scale defense of the claim that collectives which are not agents can nonetheless be subjects of collective obligation.

${ }^{9}$ My views on the metaphysics of collectives are influenced by but not identical with those in Ruben 1985.

${ }^{10}$ My thanks to a reader I am not in a position to name for insisting on clarity here.

${ }^{11}$ I am grateful to a referee for the European Journal of Philosophy for helpful comments here and to Felix Pinkert for discussion.

${ }^{12}$ For examples of such objections see De Paul, M. and Ramsey, W. 1999.

${ }^{13}$ My use of this term is influenced by Williams 1985: 93 who writes: 'There could be a way of doing philosophy which started from the way we experience our ethical life. Such a philosophy would reflect on what we believe, feel, take for granted; the ways in which we confront obligations and recognise responsibility; the sentiments of guilt and shame.' One might think I differ from Williams in focussing on what we might say rather than what we believe and feel. However, I take what people would say in this kind of situations to reflect their attempts to articulate feelings and beliefs; and I take the kind of 'reflection' on ethical experience which Williams appeals to here to involve, at a minimum, the attempt to articulate it in this way. One might also wonder why I am excluding the judgments of the philosophically curious from consideration here. The answer is that in at least some cases the reports that individuals might make as to what it is plausible to say in situations such as this are inclined might be swayed by-for example-their non-ethical metaphysical commitments on such issues as whether or not collective entities exist. 
14 See the discussion of the relationship between the terms 'phenomenology' and 'intuition' at the end of this section.

${ }^{15}$ For this reason, many of the objections to giving a role to philosophical intuition canvassed in De Paul, M. and Ramsey, W. 1999 miss the mark when applied to the position I defend.

${ }^{16}$ Although your intuition that not-p is evidence that not-p is part of the phenomenology, this does not establish that $\mathrm{p}$ is not part of the phenomenology: as I have already mentioned, there is no guarantee that the phenomenology is consistent and there may be good reasons for thinking it is not. (Thanks to David Copp for encouraging me to make this explicit)

17 Appealing to phenomenology is different from appealing to shared intuitions. In cases like this it may even involve an appeal to conflicting intuitions. Given the methodological principles I have put forward the fact that some individuals have different intuitions from mine does not constitute a knock-down objection to my view. It does leave me with the job of explaining those intuitions, something which I undertake in Sections 5-10.

${ }^{18}$ For some examples of candidate explanations, see Griffin 1996 pp. 3-4.

19 A canonical example of this is provided by discussions of objections to Utilitarianism inspired by Bernard Williams' example of Jim and the Indians (Williams 1973). I take it that the objection to utilitarianism that it conflicts with the judgments of the reflective but philosophically incurious is not unaswerable; nevertheless someone who wishes to defend Utilitarianism in the light of these judgments needs to give a plausible account of why people would make them.

20 These methodological claims are inspired by a broadly Aristotelian approach to ethics. However, they should be acceptable to non- Aristotelians. For example they would presumably be accepted by many of those who take justification in ethics to involve arriving at some form of Rawlsian reflective equilibrium between one's principles and one's judgments about particular cases. (Daniels 1979). However accepting the claims need not entail accepting that view of justification.

${ }^{21}$ For further discussion, see Williamson 2007.

${ }^{22}$ At this point it may be worth emphasising another contrast between my approach and that of Isaacs 2011. Isaacs argues (Isaacs 2011: 54-8) that we need to appeal to the notion of collective obligation to appreciate the 'moral magnitude' of collective actions such as the Rwandan genocide. While I agree that the notion of collective obligation may be illuminating in the context of mass wrong-doing, I think it is also important to note that that it is also at home in much more mundane situations. It is also not clear to me that appeal to the notion of collective obligation is the best way of explaining what is morally distintcive about genocide in particular: for an alternative view see Wringe 2006a.

${ }_{23}$ Assume that neither individual is the office manager, departmental safety officer or similar.

${ }^{24}$ For more detailed discussion see Wringe 2006b. Note that I do not claim that in all of these further cases the existence of collective obligations need be part of the 'moral phenomenology'. However, I do claim that if we are persuaded via a consideration of 'Office' that the notion of a collective obligation is legitimate, then we might find it plausible that collective obligations are also features of these other situations.

${ }^{25}$ One reader was skeptical about the idea that the philosophically incurious would have any views about how any given particular obligations is to be explained. I am simply baffled that anyone could think that appreciating the line of thought outlined in the preceding paragraph requires philosophical curiosity. 
${ }^{26}$ As attentive readers will appreciate, this paragraph constitutes an argument-as promised in Section 2-for the claim that my claims 3) and 4) form part of the moral phenomenology of Office.

${ }^{27}$ In Van Fraassen's parable a flagpole is positioned in such a way as to create a shadow of a certain length at a particular time of day. Van Fraassen 1980 chapter 3.

${ }^{28} \mathrm{I}$ am not claiming that a collective obligation could exist without any individual obligations existing at all: in what follows I shall argue that it could not.

29 This objection only has any dialectical force, if it is based on the idea this obligation is 'primitive' - that is to say, that it is not derived from some further, unspecified, more basic obligation. Someone who thinks, like me, that collective obligations are important in situations like 'Office' might accept that there is an obligation on individuals to engage in the right sort of co-operative scheme, but argue that it arises out of a collective obligation, and is, therefore, not a primitive obligation. Thanks to David Copp for forcing me to be clearer here.

${ }^{30}$ Lewis 1948.

${ }^{31}$ D. Copp, personal communication.

32 As David Copp pointed out to me.

${ }^{33}$ Many items in the recent philosophical literature on the metaphysics of collectives have fed intothis summary judgment. See footnote 6-9 for particular examples.

${ }^{34}$ I have argued elsewhere against the view that collectives can only be subject to obligations if they are agents (Wringe 2010). My views here have something in common with May 1990 who argues that collectives which are 'putative agents' are capable of having obligations. By contrast, Isaacs 2011 argues that potential agents can only have potential obligations. One problem with Isaacs' view is that it seems to suggest an individual who is a member of a collective which is a putative agent might be able to lighten the moral load on themselves without doing any wrong simply by seeing to it that the putative agent's capacity for agency was never realised. Since the only obligations which are unsatisfied in such a case would be merely potential obligations it is hard to see where the wrongdoing here could lie. But there is something implausible about the idea that agents can permissibly lighten their moral load in this way. I thank an anonymous referee for the European Journal of Philosophy for insisting on clarification here.

${ }^{35}$ Many thanks to David Copp for helpful discussion of this point in correspondence.

36 This point does not rely on the idea that mental states causally explain action; merely that they explain them in some non-vacuous manner. This is important, in the current context, since although collective obligations can explain individual obligations, they do not provide causal explanations of them.

${ }^{37}$ I owe this example to my colleague, Lars Vinx.

38 The name was suggested by David Copp.

${ }^{39}$ Copp 2006.

${ }^{40}$ Pettit and McDonald 1981.

${ }^{41}$ Copp 2006.

${ }^{42}$ Kant, 1785/1993: 40 /AK 434.

${ }^{43}$ Kant 1785/1993: 27 /AK 417.

${ }^{44} \mathrm{I}$ am indebted to discussions with my former colleague, Lucas Thorpe at several points in this paragraph.

${ }^{45}$ Kim 1993 passim.

${ }^{46}$ For short presentations see in particular Kim 1989a, b reprinted in Kim 1993. 
${ }^{47}$ In questions, when I presented a much earlier version of this part of the paper in the Open Sessions of the Joint Session of the Mind Association and Aristotleian Society in 2006 .

48 As Lars Vinx (I think) pointed out to me.

${ }^{49} \mathrm{I}$ am grateful to an anonymous referee for the European Journal of Philosophy and to seminar audiences at Bilkent, Boğaziçi and Oxford Brookes Universities and at the University of Keele and to conference audiences in Istanbul (twice), Southampton, and Helsinki for extremely illuminating discussions of earlier drafts of this paper. I am especially grateful to David Copp for a set of detailed written comments which enabled me to improve the paper immensely and to Felix Pinkert fo several very helpful discussions of related issues.

\section{REFERENCES}

Copp, D. (2006), 'On the Agency of Certain Collective Entities: An Argument from "Normative Autonomy" ', Midwest Studies in Philosophy, 30: 194-221.

Daniels, N. (1979), 'Wide Reflective Equilibrium and Theory Acceptance in Ethics', Journal of Philosophy, 76: 256-82.

De Paul, M. and Ramsey, W. (eds) (1999), Rethinking Intuition: The Psychology of Intuition and its Role in Philosophical Inquiry. Lanham, MD: Rowman and Littlefield.

French, P. (1984), Collective and Corporate Responsibility. New York: Columbia University Press.

Geuss, R. (2010), Politics and the Imagination. Cambridge: Cambridge University Press.

Gilbert, M. (2008), Membership, Commitment, and the Bounds of Obligation. Oxford: Oxford University Press.

Griffin, J. (1996), Value Judgment: Improving Our Ethical Beliefs. Oxford: Clarendon Press.

Isaacs, T. (2011), Moral Responsibility in Collective Contexts. Oxford: Oxford University Press.

Kant, I. (1785/1993), Grundlegung der Metaphysik der Sitten translated as Grounding for the Metaphysic of Morals. J. Ellington (ed.) Indianapolis: Hackett.

Kim, J. (1989a), 'Mechanism, Purpose and Explanatory Exclusion', Philosophical Perspectives, 3: 77-105.

— (1989b), 'The Myth of Non-Reductive Materialism', Proceedings and Addresses of the American Philosophical Association, 63: 31-47.

- (1993), Supervenience and Mind. Cambridge: Cambridge University Press.

Lewis, H. (1948), 'Collective Responsibility', Philosophy, 23: 3-18.

May, L. (1990), 'Collective Action and Shared Responsibility', Nous, 24: 269-78.

Pettit, P. (2007), 'Responsibility Incorporated', Ethics, 117: 171-201.

_ and McDonald, G. (1981), Semantics and Social Science. London: Routledge and Kegan Paul.

Ruben, D.-H. (1985), The Metaphysics of the Social World. London: Routledge and Kegan Paul.

Tollefsen, D. (2003), 'Participant Reactive Attitudes and Collective Responsibility', Philosophical Explorations, 6: 218-34.

— (2006), 'The Rationality of Collective Guilt', Midwest Studies in Philosophy, 30: 22240.

Van Fraassen, B. (1980), The Scientific Image. Oxford: Clarendon Press.

(C) 2014 John Wiley \& Sons Ltd 
Williams, B. (1973), 'A Critique of Utilitarianism', in B. Williams and J. Smart (eds) Utilitarianism: For and Against. Cambridge: Cambridge University Press, 77-149. (1985), Ethics and the Limits of Philosophy. London: Collins.

Williamson, T. (2007), The Philosophy of Philosophy. Oxford: Blackwell.

Wringe, B. (2006a), 'Collective Action and the Peculiar Evil of Genocide', Metaphilosophy, 2006: 376-92.

- (2006b), 'Needs, Rights and Collective Obligations', in S. Reader (ed.) The Philosophy of Need. Supplement to Philosophy. Cambridge: Cambridge University Press, 187-2005.

(2010), 'Global Obligations and the Agency Objection', Ratio, 2010: 217-31. 